\title{
Penggunaan Analisis Multidimensional Scaling Untuk Mengetahui Kemiripan Rumah Makan Di Manado Town Square Berdasarkan Kerakteristik Pelanggan
}

\author{
${ }^{1}$ Gloria A Walundungo, ${ }^{2}$ Marline Paendong, ${ }^{3}$ Tohap Manurung \\ ${ }^{1}$ Program Studi Matematika, F-MIPA, UNSRAT, gloriawalundungo@ yahoo.co.id \\ ${ }^{2}$ Program Studi Matematika, F-MIPA, UNSRAT, marline_paendong @yahoo.com \\ ${ }^{3}$ Program Studi Matematika, F-MIPA, UNSRAT, kris_ton79@yahoo.com
}

\begin{abstract}
Multidimensional Scaling (MDS) is a technique that can be used in multiple variables to determine the position of other objects based on similarity assessment. The purpose of this study is to obtain a description of the restaurant and the customers know the similarities between the restaurants as object of research. The result of Multidimensional Scaling map shows that WarungPojok and Solaria restaurant have a same rate in taste of food category due to the distance is near each other. As for the restaurant Bakmi Naga, Ayam Penyet and Kawan Baru have relative position between each other which means the three restaurants unsimillarity.
\end{abstract}

Keywords : Multidimensional Scaling, Mapping, Map Perception, Restaurant

\begin{abstract}
Abstrak
Multidimensional Scalling (MDS)merupakan salah satu teknik peubah ganda yang dapat digunakan untuk menentukan posisi suatu objek lainnya berdasarkan penilaian kemiripannya. Tujuan dari penelitian ini adalah untuk memperoleh deskripsi pelanggan terhadap rumah makan serta mengetahui kemir ipan antara rumah makan yang dijadikan objek penelitian. Hasil dari peta analisis Multidimensional Scaling dapat dilihat bahwa rumah makan Warung Pojok dan Solaria memiliki tingkat kemiripan di cita rasa makanankarena jarak yang saling berdekatan. Sedangkan untuk rumah makan Bakmi Naga, Ayam Penyet dan Kawan Baru menempati posisi re latif saling berjauhan antar satu dengan yang lain yang berarti ketiga rumah makan ini tidak mempunyai kemiripan atau ketakmiripan.
\end{abstract}

Kata kunci : Multidimensional Scaling, Pemetaan, Peta Persepsi, Ru mah Makan

\section{Pendahuluan}

Dalam era globalisasi ini persaingan bisnis akan menjadi sangat ketat. Salah satu bisnis yang terus berkembang di Indonesia adalah bisnis makanan. Hal ini disebabkan karena semua orang membutuhkan makanan sehingga secara otomatis bisnis restoran selalu dicari orang. Seiring dengan perubahan zaman, kecenderungan orang untuk makan diluar rumah semakin meningkat dengan berbagai alasan praktis, ekonomis maupun prestige. Oleh karena itu, sangat penting bagi sebuah rumah makan untuk mempertimbangkan strategi rumah makan untuk menciptakan suasana yang nyaman dan dapat mengungguli rumah makan lainnya.

Restoran atau rumah makan adalah suatu operasi layanan makanan yang mendatangkan keuntungan yang basis utamanya adalah penjualan makanan dan minuman kepada individu-individu dan tamu-tamu dalam kelompok kecil. Secara umum faktor yang mempengaruhi keberhasilan bisnis restoran adalah kualitas cita rasa (taste) yang sesuai selera masyarakat, pemilihan lokasi yang tepat, disertai pelayanannya [3]. Dan untuk pengertian dari pelanggan yaitu individu-individu yang melakukan pembelian untuk memenuhi kebutuhan pribadinya atau konsumsi rumah tangga [4].

Analisis Multidimensional Scaling (MDS) merupakan salah satu teknik peubah ganda yang dapat digunakan untuk menentukan posisi suatu objek lainnya berdasarkan penilaian kemiripannya. $M D S$ berhubungan dengan pembuatan map untuk menggambarkan pos is i sebuah objek dengan objek lainnya berdasarkan kemiripan objek-objek tersebut.

Tujuan dari penelitian ini adalah untuk memperoleh deskripsi tentang persepsi pelanggan terhadap rumah makan yang ada di Manado Town Square serta untuk mengetahui kemiripan antara 
rumah makan yang ada di Manado Town Square dengan menggunakan analisis Multidimensional Scaling.

\section{Analis is Multidimensional Scaling (MDS)}

Analisis multidimensional scaling merupakan salah satu teknik peubah ganda yang dapat digunakan untuk menentukan posisi suatu objek la innya berdasarkan penilaian kemiripannya.

MDS digunakan untuk mengetahui hubungan interdepensi atau saling ketergantungan antar variabel atau data. MDS dibedakan atas MDS berskala metrik dan MDS berskala non-metrik.

Multidimensional Scaling adalah : [5]

1. Kumpulan teknik-teknik statistika untuk menganalisis kemiripan dan ketakmiripan antar objek.

2. Memberikan hasil yang berupa plot titik-titik sehingga jarak antar titik menggambarkan tingkat kemiripan atau ketakmiripan.

3. Memberikan petunjuk untuk mengidentifikasi peubah tak diketahui atau faktor yang mempengaruhi munculnya kemiripan atau ketakmiripan.

Tujuan dari multidimensional scaling adalah menemukan suatu konfigurasi sedemikian sehingga jarak antar titik sesuai dengan ketakmiripan antar objek [2].

\subsection{Jenis-Jenis Multidimensional Scaling (MDS)}

Menurut [1] untuk melakukan analisis data MDS digunakan nilai-nilai yang menggambarkan tingkat kemiripan atau tingkat ketakmiripan antar objek yang disebut proximity yang terbagi atas similarity (kemiripan) dan dissimilarity (ketakmiripan). Berdasarkan tipe data tersebut, MDS dibagi menjadi dua yaitu multidimensional scaling metrik dan multidimensional scaling non-metrik.

\subsubsection{Multidimensional Scaling Metrik}

Data jarak yang digunakan dalam penskalaan berdimensi ganda metrik adalah data rasio. Penskalaan berdimensi ganda metrik digunakan untuk menemukan himpunan titik dalam ruang dimensi $n$ dimana masing-masing titik mewakili satu objek sehingga jarak antar titik adalah $d_{r t} \approx f\left(d_{r t}\right)$, dimana $f$ adalah fungsi monotonic parametric kontinu.

\subsubsection{Multidimensional Scaling Non-Metrik}

Data jarak yang digunakan dalam penskalaan berdimensi ganda non-metrik adalah data yang dianggap bertipe ordinal. Untuk penskalaan berdimensi ganda non-metrik, fungsi transformasi hanya mempunyai batasan $\delta_{r t}<\delta_{r / t} \Rightarrow f\left(\delta_{r t}\right) \leq f\left(\delta_{r t t}\right)$ untuk semua $1 \leq r, t, r^{\prime}, t^{\prime} \leq n$. Suatu fungsi STRESS (Standardized Residual Sum of Square) sebagai berikut:

$$
\text { Stress }=\sqrt{\frac{\sum_{r, t}\left(d_{r t}-\hat{d}_{r t}\right)^{2}}{\Sigma_{r, t} d_{r t}^{2}}}
$$

\section{Metode Penelitian}

Penelitian ini menggunakan data primer yang diperoleh dari kuesioner. Responden dalam penelitian ini ialah pelanggan yang pernah berkunjung ke rumah makan yang ada di Manado Town Square. Dan jumlah responden dalam penelitian adalah 100 responden, dimana setiap rumah makan terdapat masing-masing 20 responden. Penelitian ini menggunakan software SPSS 20.

Adapun objek pengamatan yang dite liti yaitu Kawan Baru, Bakmi Naga, Warung Pojok, Solaria dan Ayam Penyet. Dalam penelitian ini menggunakan teknik scoring skala likert, yaitu pertanyaanpertanyaan yang memberikan lima alternatif pilihan yang diberi skor sebagai berikut : 
1. Sangat setuju

2. Setuju

3. Kurang setuju

4. Tidak setuju

5. Sangat tidak setuju diberi skor 5

diberi skor 4

diberi skor 3

diberi skor 2

diberi skor 1

Tabel 1. Peubah-Peubah yang Diamati

\begin{tabular}{|l|l|}
\hline Peubah & \multicolumn{1}{|c|}{ Definisi } \\
\hline X1 & Harga yang ditawarkan terjangkau \\
\hline X2 & Mutu makanan yang diberikan sesuai dengan keinginan \\
\hline X4 & Porsi makanan yang disajikan lebih banyak \\
\hline X5 & Jenis makanan bervariasi \\
\hline X6 & Makanan yang tersedia bercita rasa tinggi \\
\hline X7 & Penyajian makanan yang disajikan tertata rapi \\
\hline X8 & Penyajian makanan selalu bersih \\
\hline X9 & Makanan yang disajikan selalu segar dan baru \\
\hline X10 & Rasa makanan yang ditawarkan tidak berubah-ubah \\
\hline X11 & Rasa dari makanan yang disajikan sesuai selera pelanggan \\
\hline X12 & Anda sangat puas dengan makanan yang diberikan \\
\hline X13 & Proses penyajian makanan yang tepat waktu \\
\hline X14 & Pelayan ramah dalam melayani pelanggan \\
\hline X15 & Pelayan sabar dalam menghadapi pelanggan \\
\hline X16 & Pelayan terampil dalam melayani pelanggan \\
\hline X17 & Keamanan terjamin \\
\hline X18 & Kebersihan rumah makan terjaga \\
\hline X19 & Ingin kembali lagi mencicipi makanan \\
\hline X20 & Penataan interior dan eksterior rumah makan menarik \\
\hline & Rumah makan tersebut dijadikan tempat favorit \\
\hline &
\end{tabular}

\section{Hasil dan Pembahasan}

\subsection{Analisis Multidimensional Scaling}

Hasil dari pengolahan program MDS ini didapatkan koordinat (stimulus coordinates) masing-masing rumah makan yang ditunjukkan pada table dibawah ini :

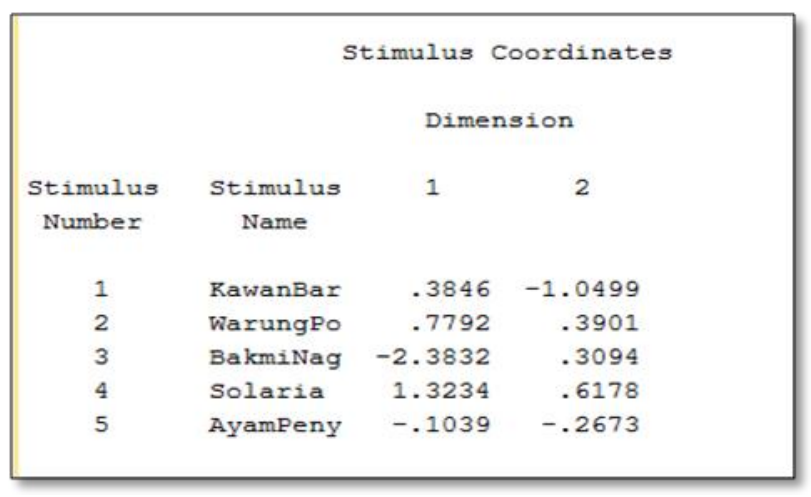

Gambar 1. Stimulus Coordinates untuk ke lima ru mah makan 
Berdasarkan koordinat dari table diatas, dapat dihasilkan peta posisi dari masing-masing rumah makan dengan konfigurasi seperti gambar dibawah ini :

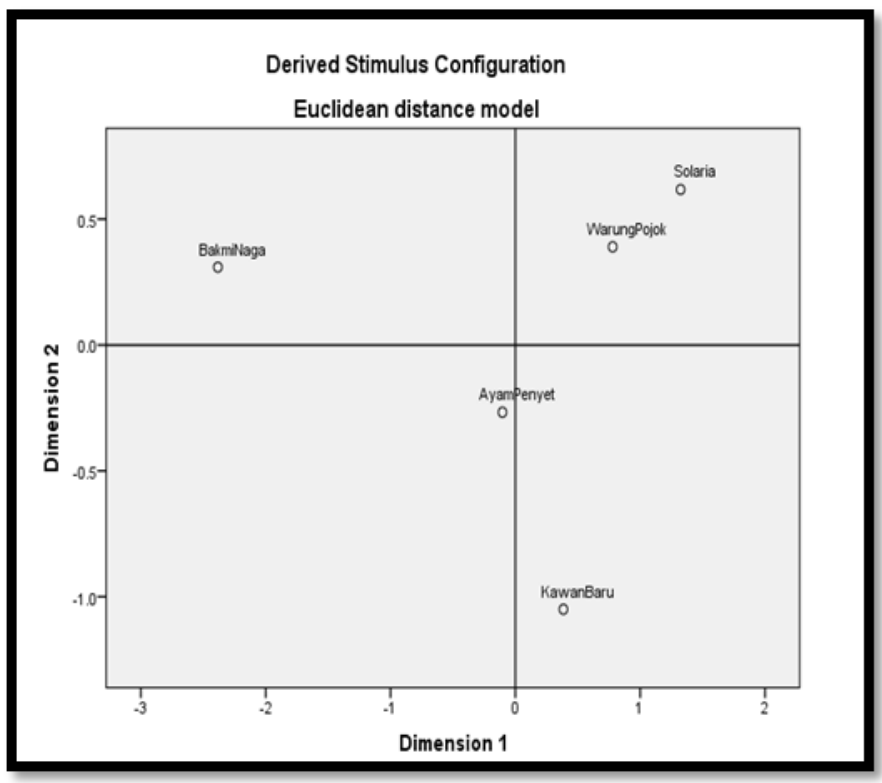

Gambar 2 Peta Posisi Rumah Makan

Ini adalah peta hasil ALSCAL untuk menampilkan map MDS. Terlihat bahwa rumah makan Solaria mempunyai kemiripan dengan rumah makan Warung Pojok. Karena jarak paling berdekatan dan berada pada kuadran yang sama. Kemiripan dari kedua rumah makan tersebut dapat dilihat dari tabel stimulus coordinates:

\begin{tabular}{|c|c|c|c|c|c|c|c|}
\hline \multirow[b]{2}{*}{$\begin{array}{l}\text { Stimulus } \\
\text { Number }\end{array}$} & \multicolumn{4}{|c|}{ Dimension } & & & \\
\hline & $\begin{array}{l}\text { Stimulus } \\
\text { Name }\end{array}$ & 1 & 2 & & & & \\
\hline 1 & $\mathrm{x} 1$ wp & -.7356 & -.2284 & 25 & x13wp & -.2328 & -.1015 \\
\hline 2 & x1so & .6062 & -2.5380 & 26 & x13so & -.7126 & -.8662 \\
\hline $\begin{array}{l}3 \\
4\end{array}$ & $\begin{array}{l}x 2 w p \\
x 2 s 0\end{array}$ & $\begin{array}{r}.2917 \\
1.9405\end{array}$ & $\begin{array}{l}-1.4364 \\
-1.0187\end{array}$ & 27 & $\mathrm{x} 14 \mathrm{wp}$ & -.5308 & .1889 \\
\hline 5 & $\times 3 w p$ & -.3036 & -.1329 & 28 & $\mathrm{x} 1430$ & .3298 & .6660 \\
\hline $\begin{array}{l}6 \\
7\end{array}$ & $\begin{array}{l}\times 3 s 0 \\
\times 4 \text { wp }\end{array}$ & $\begin{array}{l}-.5226 \\
-.2270\end{array}$ & $\begin{array}{r}.1442 \\
-.3797\end{array}$ & 29 & $\mathrm{x} 15 \mathrm{wp}$ & -.2300 & 1.4933 \\
\hline 8 & $\times 4 s 0$ & -.8556 & .1010 & 30 & x15so & -1.6140 & .6629 \\
\hline 9 & $x 5$ wp & -.3799 & -.3741 & 31 & $\mathrm{x} 16 \mathrm{wp}$ & -.7703 & .2731 \\
\hline $\begin{array}{l}10 \\
11\end{array}$ & $\begin{array}{l}x 5 s 0 \\
x 6 \text { wp }\end{array}$ & $\begin{array}{r}-.8495 \\
.3039\end{array}$ & $\begin{array}{r}.0868 \\
1.3375\end{array}$ & 32 & $x 16=$ & 25483 & -.9794 \\
\hline 12 & $\times 6 s 0$ & .4971 & -1.4020 & 32 & X1630 & 2.5483 & $-.9 / 94$ \\
\hline 13 & $\times 7 \mathrm{wp}$ & -.1946 & -.3383 & 33 & $\mathrm{x} 17 \mathrm{wp}$ & -.7263 & .0361 \\
\hline 14 & $\times 7 s 0$ & -.3188 & -.0990 & 34 & $\mathrm{x} 1780$ & .3664 & 1.7983 \\
\hline $\begin{array}{l}15 \\
16\end{array}$ & $\begin{array}{l}x 8 w p \\
x 8 s 0\end{array}$ & $\begin{array}{l}-.2004 \\
-.3624\end{array}$ & $\begin{array}{l}-.2889 \\
-.2291\end{array}$ & 35 & $\mathrm{x} 18 \mathrm{wp}$ & -1.6854 & -.2483 \\
\hline 17 & $\times 9$ wp & -1.0711 & -.2636 & 36 & $\mathrm{x} 1830$ & -1.7917 & .2889 \\
\hline $\begin{array}{l}18 \\
19\end{array}$ & $\begin{array}{l}\text { x9so } \\
\text { x10wp }\end{array}$ & $\begin{array}{r}-.1609 \\
.9833\end{array}$ & $\begin{array}{l}-.3044 \\
1.1979\end{array}$ & 37 & x19wp & .6848 & 1.3132 \\
\hline 20 & x10so & 1.3293 & 1.2789 & 38 & x19so & -1.3135 & .3407 \\
\hline $\begin{array}{l}21 \\
22\end{array}$ & $\begin{array}{l}\text { x11wp } \\
\text { x11so }\end{array}$ & $\begin{array}{l}2.5470 \\
-.6782\end{array}$ & $\begin{array}{r}.7196 \\
-.0095\end{array}$ & 39 & $\mathrm{x} 20 \mathrm{wp}$ & .8948 & -1.6579 \\
\hline 23 & $\mathrm{x} 12 \mathrm{wp}$ & 2.6570 & -.4117 & 40 & x20зо & -.6902 & .1170 \\
\hline 24 & x12so & 1.1777 & 1.2638 & & & & \\
\hline
\end{tabular}

Gambar 3. Stimulus Coordinates untuk rumah makan Warung Pojok dan Solaria

Dapat digunakan criteria Size Difference untuk mengetahui selisih-selis ih dari hasil dimensi 1 dan dimensi 2 yang mempunyai besaran berkisar antara $0-1$. Untuk memperoleh hasil yang 
menunjukkan tingkat kemiripan dari masing-masing karakteristik yang telah dibandingkan, maka harus memperoleh selisih yang mendekati 0. Sesuai dengan gambar (3), maka kemiripan dari kedua rumah makan ini adalah:

1. Porsi makanan yang disajikan lebih banyak (x3).

Pada dimensi 1 :

Warung Pojok $=-0,3036$

Solaria $\quad=-0,5226$

Selisih $\quad=0,219$

Pada dimensi 2 :

Warung Pojok = $=-0,1329$

Solaria $\quad=0,1442$

Selisih $\quad=-0,277$

2. Makanan yang tersedia bercita rasa tinggi (x5).

Pada dimensi 1 :

Warung Pojok $=-0,3799$

Solaria $\quad=0,8495$

Selisih $\quad=0,4696$

Pada dimensi 2 :

Warung Pojok = $=-0,3741$

Solaria $\quad=0,0868$

Selisih $\quad=-0,4609$

3. Penyajian makanan selalu bersih (x7).

Pada dimensi 1 :

Warung Pojok = $=-0,1946$

Solaria $\quad=-0,3188$

Selisih $\quad=0,1242$

Pada dimensi 2 :

Warung Pojok $=-0,3383$

Solaria $\quad=-0,0990$

Selisih $\quad=-0,2393$

4. Makanan yang disajikan selalu segar dan baru (x8).

Pada dimensi 1 :

Warung Pojok $=-0,2004$

Solaria $\quad=0,3624$

Selisih $\quad=0,162$

Pada dimensi 2 :

Warung Pojok $=-0,2889$

Solaria $\quad=-0,2291$

Selisih $\quad=-0,0598$

5. Rasa dari makanan yang disajikan sesuai selera pelanggan (x10).

Pada dimensi 1 :

Warung Pojok $\quad=0,9833$

Solaria $\quad=1,3293$

Selisih $\quad=-0,346$

Pada dimensi 2 :

Warung Pojok $=1,1979$

Solaria $\quad=1,2789$

Selisih $\quad=-0,081$ 
6. Ingin kembali lagi mencicipi makanan (x18).

Pada dimensi 1 :

Warung Pojok $\quad=-1,6854$

Solaria $\quad=-1,7917$

Selisih $\quad=0,1063$

Pada dimensi 2 :

Warung Pojok $=-0,2483$

Solaria $\quad=0,2889$

Selisih $\quad=-0,5372$

Setelah dilakukan perhitungan untuk semua dimensi 1 dan dimensi 2 yang jumlah keseluruhannya ada 40 karakteristik, maka diperoleh 6 karakteristik yang memiliki angka selisih mendekati 0 yang artinya mempunyai perbedaan yang sangat kecil. Dengan demikian keenam karakteristik yang tersebut untuk rumah makan Warung Pojok dan Solaria mempunyai kemiripan.

\section{Kesimpulan}

Peta hasil analisis Multidimensional Scaling (MDS) dapat dilihat bahwa rumah makan Warung Pojok dan Solaria memiliki tingkat kemiripan yaitu pada x3, x5, x7, x8, x10, dan x18 karena jarak yang saling berdekatan. Sedangkan untuk rumah makan bakmi naga, ayam penyet dan kawan baru menempati posisi relatif saling berjauhan antar satu dengan yang lain. Hal ini berarti rumah makan bakmi naga, ayam penyet dan kawan baru tidak mempunyai kemiripan atau ketakmiripan.

\section{Daftar Pustaka}

[1] Ginanjar, I. 2008. Aplikasi Multidimensional Scaling (MDS) Untuk Peningkatan Pelayanan Proses Belajar Mengajar (PBM). Staf Pengajar Jurusan Statistika FMIPA UNPAD, Bandung.

[2] Jawoiska, N. dan Anastasova, A. C. (2009). A Review of Multidimensional Scaling (MDS) and its Utility in Various Psychological Domains. Journal Tutorials in Quantitative Methods for Psychology. Vol. 5 (1), p. $1-10$.

[3] Ninemeier, J.D. dan Hayes. 2006. Analisis Karakteristik Demografis Pengunjung Restoran [Online]. Tersedia : http : // digilib. petra. ac. id/ jiunkpe/s 1/hot1/2007/jiunkpe-ns-sl-2007-334020066-5659fastfood-chapter2.pdf. [10 April 2009]

[4] Swasta, Basu Dharmmesta dan T Hani Handoko. 1997. Manajemen Pemasaran : Analisa Perilaku Konsumen. Yogyakarta : BPFE.

[5] Timm, N. H. 2002. Applied Multivariate Analysis. Springer-Verleg. New York 